\title{
IRON ENZYMES IN IRON DEFICIENCY. VI. ACONITASE ACTIVITY AND CITRATE METABOLISM
}

\author{
BY ERNEST BEUTLER
}

\author{
(Irom the Argonne Cancer Research Hospital, operated by The University of Chicago for the \\ United States Atomic Energy Commission, and the Department of Medicine, \\ The University of Chicago, Chicago, Ill.)
}

(Submitted for publication April 7, 1959; accepted June 1, 1959)

Iron serves vital functions in the economy of the body in a variety of ways. Its role as an integral part of biologically important substances is well known. In heme, it forms a part of the oxygen-carrying compounds, hemoglobin and myoglobin, and of the cytochromes, cytochrome oxidase, catalase and perioxidase. Another enzyme, succinic dehydrogenase, appears to contain iron (1), but not bound as heme. Physiologic vasodepressor activity has also been ascribed to the iron storage compound, ferritin (2). Less well known, perhaps, is the relatively recently described function of iron as a cofactor in several important enzymatic reactions (3-5). Knowledge of this function of iron served as the basis for the current investigation.

In previous studies of the pathologic physiology of the iron-deficiency state, we have examined the fate of the heme compounds: hemoglobin, cytochrome c $(6,7)$, catalase $(7,8)$, cytochrome oxidase (9), and succinic dehydrogenase (10). Contrary to the earlier conclusions of $\mathrm{Hahn}$ and Whipple (11), but in agreement with those of Gubler, Cartwright and Wintrobe (12), we found that varying degrees of depletion in several iron enzymes occurred in the iron-deficiency state. In the current study, we have undertaken measurement of aconitase, an enzyme that is not known to contain iron, but that appears to require iron as a specific cofactor (5). Dialyzed solutions of aconitase lose their activity. Dickman and Cloutier (5) demonstrated that the addition of iron and a reducing agent reactivated the enzyme. None of the many other ions tested had the capacity to reactivate aconitase $(5,13)$.

Aconitase catalyzes the biologically important equilibrium between citrate, isocitrate and cisaconitase. Takeda and Hara (14) have reported that activity of aconitase is diminished in livers of guinea pigs poisoned with $\alpha$ - $\alpha^{\prime}$-dipyridyl, and that marked citric acid diuresis occurred in these animals, especially after loading with citrate and butyrate. While we cannot accept Takeda's implication that $\alpha$ - $\alpha^{\prime}$-dipyridyl-poisoned animals are iron-deficient in a sense in any way comparable to iron deficiency produced by bleeding or by a low iron diet, it seemed worthwhile to explore aconitase activity and the metabolism of exogenously administered citrate in truly iron-deficient animals and humans.

\section{MATERIALS AND METHODS}

Unless otherwise indicated, female Holtzman strain rats have been used throughout these experiments. All animals were fed the iron-poor diet that we have described previously (7), and were given water rendered iron free by passing it over an ion exchange resin. Unless otherwise indicated, each control rat was given 25 mg. of iron, as iron-dextran (Imferon $\left.{ }^{\circledR}\right), 1$ intramuscularly into the hamstring muscles in two divided doses, one at the beginning of the experiment, the other, two weeks later. The animals were not fasted prior to sacrifice. Each animal was exsanguinated from the heart under ether anesthesia. All of the organs that were removed were placed into chilled vessels.

The method of aconitase assay was based on that described by Anfinsen (15). Tissues were homogenized in ice cold $0.2 \mathrm{M}$ phosphate buffer, $\mathrm{pH} 7.40$, with a PotterElvejhem type homogenizer, and the diluted homogenate was filtered through Schleicher and Schuell No. 604 filter paper. Filtrates were kept at $0^{\circ} \mathrm{C}$. and assays were carried out within an hour. Unless otherwise stated, 0.1 and $0.2 \mathrm{ml}$. aliquots of filtered tissue homogenate were

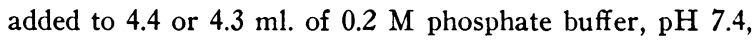
in a $37^{\circ} \mathrm{C}$. water bath. The reaction was started by the addition of substrate, $0.5 \mathrm{ml}$. of cis-aconitate solution. The substrate was freshly prepared for each assay by allowing an aqueous solution of cis-aconitic acid anhydride (Sigma Chemical Corporation) to remain at room temperature for one hour, then neutralizing with $0.1 \mathrm{ml} .2 \mathrm{~N}$ $\mathrm{NaOH}$ per $2.76 \mathrm{mg}$. anhydride. The volume was then adjusted with buffer to give a concentration of $15.6 \mathrm{mg}$.

${ }^{1}$ Supplied through the courtesy of Lakeside Laboratories, Milwaukee, Wisconsin. 


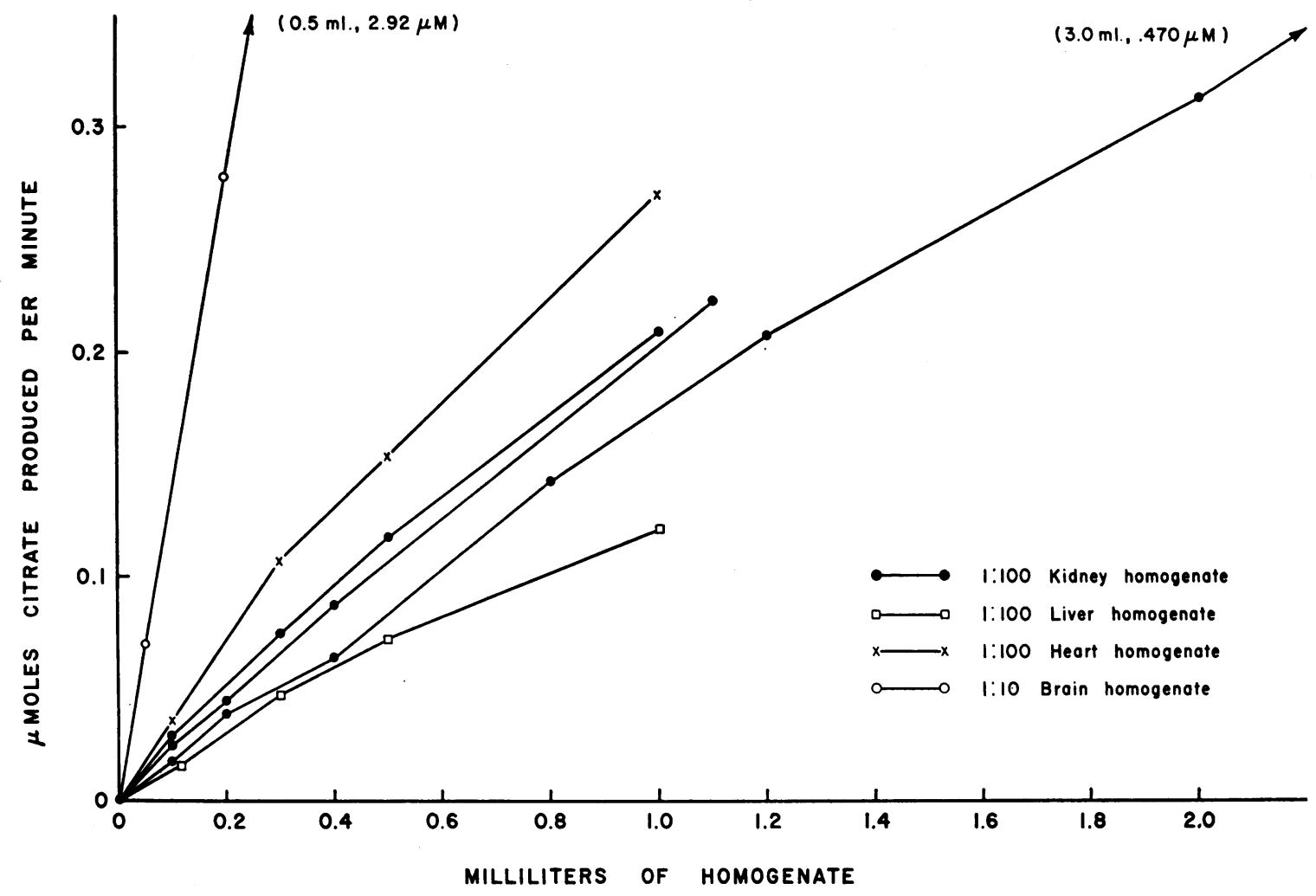

Fig. 1. The Relationship Between the Amount of Citrate Produced from Cis-Aconitate and the Volume of Homogenate AdDED

Assay system : cis-aconitate, $7.8 \mathrm{mg}$. (as anhydride) ; tissue homogenate, as indicated; final volume $5 \mathrm{ml}$. in $0.2 \mathrm{M}$ phosphate buffer, $\mathrm{pH} 7.4$; temperature $37^{\circ} \mathrm{C}$.

(as anhydride) per $\mathrm{ml}$. Fifteen minutes after addition of substrate, the reaction was stopped. In the case of heart, kidney and liver, this was done by adding $1 \mathrm{ml}$. of the reaction mixture to $0.5 \mathrm{ml}$. of 50 per cent $(\mathrm{V} / \mathrm{V})$ sulfuric acid in a tube marked at the $10 \mathrm{ml}$. mark. The total volume was then brought to approximately $5 \mathrm{ml}$. with distilled water. In the case of brain homogenate, the reaction was stopped by adding $5 \mathrm{ml}$. of 20 per cent trichloracetic acid to the entire $5 \mathrm{ml}$. reaction mixture; citric acid determinations were done on $5 \mathrm{ml}$. of the filtrate. Citric acid determinations were carried out according to our modification of the pentabromacetone method (16). In this assay system, the quantity of citric acid produced is approximately linear with respect to time of reaction and to volume of tissue extract added (Figure 1). One unit of enzyme activity has been defined arbitrarily as that amount of enzyme that will, in the assay system described, convert $10^{-7}$ Moles of cis-aconitic acid to citric acid per minute. ${ }^{2}$ Because of the slight de-

2 In two experiments, an assay system containing 3.9 mg. cis-aconitic acid as an anhydride was used. It had been determined empirically that one unit of enzyme in this system converts $0.85 \times 10^{-7}$ Moles of cis-aconitic acid to citrate per minute. parture from linearity that was sometimes observed when the amount of citric acid formed was compared with the amount of tissue extract added (Figure 1), two dilutions of tissue were assayed. These dilutions were chosen so that one sample usually contained less than one unit and the other contained more than one unit of enzyme activity. The average of these two determinations has been reported. One-tenth and $0.2 \mathrm{ml}$. of the following tissue dilutions were found to be appropriate: kidney, 1 to 25 or 1 to 40 ; heart, 1 to 50 ; brain, 1 to 20 ; liver, 1 to 20 .

The method used for assaying the aconitase activity of human white cells has been described in detail elsewhere (17).

\section{EXPERIMENTAL AND RESULTS}

\section{A. The reactivation of aconitase by iron}

A one to 800 homogenate was prepared from the kidney of a normal rat in $0.2 \mathrm{M}$ phosphate buffer, $\mathrm{pH} 7.4$ The aconitase activity of the homogenate was assayed immediately and at intervals after incubation at $37^{\circ} \mathrm{C}$. Solutions containing $0.03 \mathrm{M}$ ferrous sulfate, $0.03 \mathrm{M}$ ascorbic 
acid, and both were prepared and their $\mathrm{pH}$ adjusted to 7.4. After one hour, one volume of one of each of these solutions was added to each of three nine-volume aliquots of the incubating mixture. As a control, one volume of buffer was added to a fourth aliquot. Aconitase activity was determined at intervals. The results of this experiment, showing the time course of partial reactivation of aconitase by iron and ascorbate, are shown in Figure 2. No reactivation was achieved by the addition of either iron or ascorbate alone.

The effect of different concentrations of iron and ascorbic acid has been investigated in a similar fashion. In three experiments, one to 800 kidney homogenate, 75 to 80 per cent inactivated by incubating for one hour at $37^{\circ} \mathrm{C}$., was reactivated for 10 minutes with iron and ascorbate. Aconitate was then added and enzyme activity measured in the usual manner. It is apparent that complete reactivation of incubated enzyme could be achieved regularly when sufficiently high concentrations of iron and ascorbic acid were used. The results of these studies are given in Figure 3.

\section{B. Aconitase activity of organs of normal and iron-deficient rats}

Four 23-day-old rats were sacrificed and the hemoglobin, hematocrit and plasma iron values and aconitase activity of kidneys, hearts and livers were determined. Eighteen 23-day-old rats were given an iron-poor diet, nine of these being injected with iron-dextran. After 10 days, four iron-deficient and four iron-treated (control) rats were sacrificed, and after 26 days, the remaining five iron-deficient and five iron-treated (control) animals were sacrified. The hemoglobin, hematocrit and plasma iron values and organ aconitase assays of these animals are presented in Table I. A well-marked decrease in aconitase activity of the kidneys of the iron-deficient animals, compared with that of the control animals, was found. In sharp contrast, the aconitase activity of the other organs studied was normal, with the possible exception of a slight reduction of heart enzymatic activity. The enzymatic activity of mixtures of equal volumes of homogenates from iron-deficient and normal animals was the arithmetic mean of the two: no inhibition of normal kidney enzyme or activation of iron-deficient kidney enzyme could be demonstrated. Rats that had always been fed stock diet had kidney aconitase activity comparable with that of the irondextran controls. Administration of iron-dextran to such rats did not cause an elevation of kidney aconitase activity.

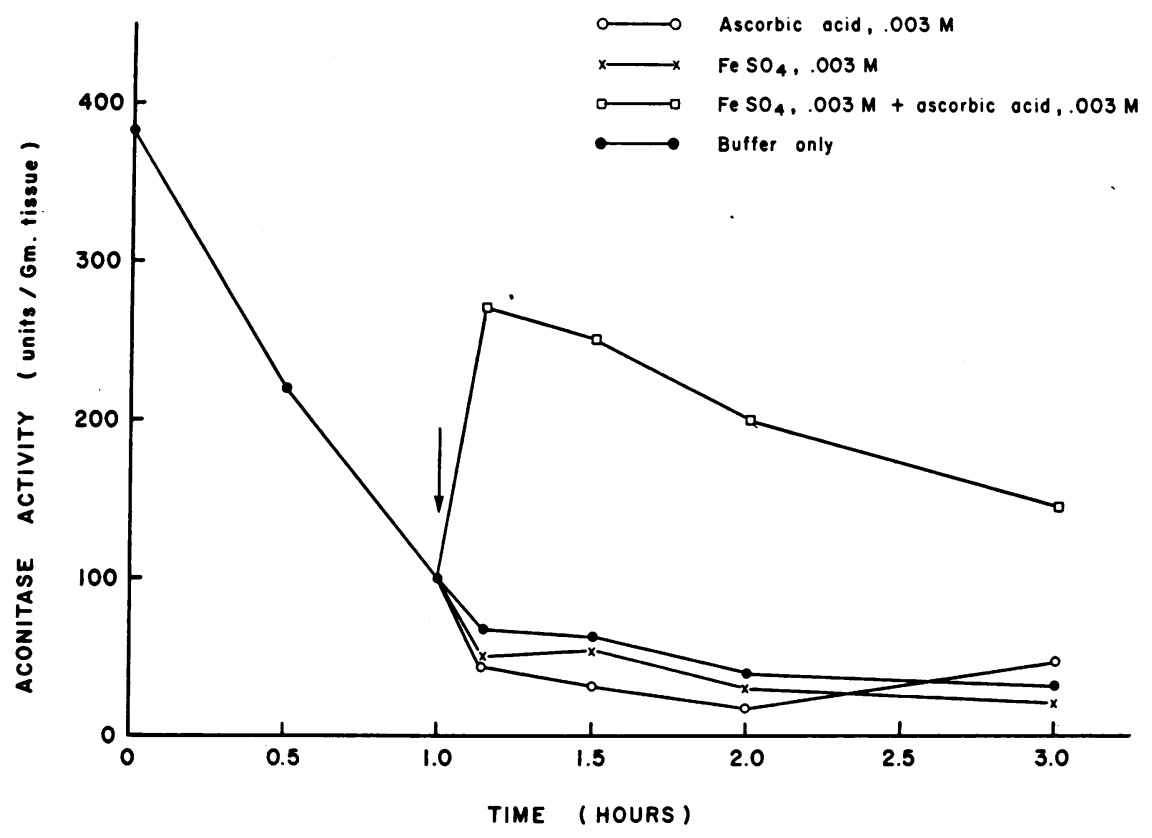

Fig. 2. The Reactivation of Aconitase by Iron and Ascorbic Acid 
ERNEST BEUTLER

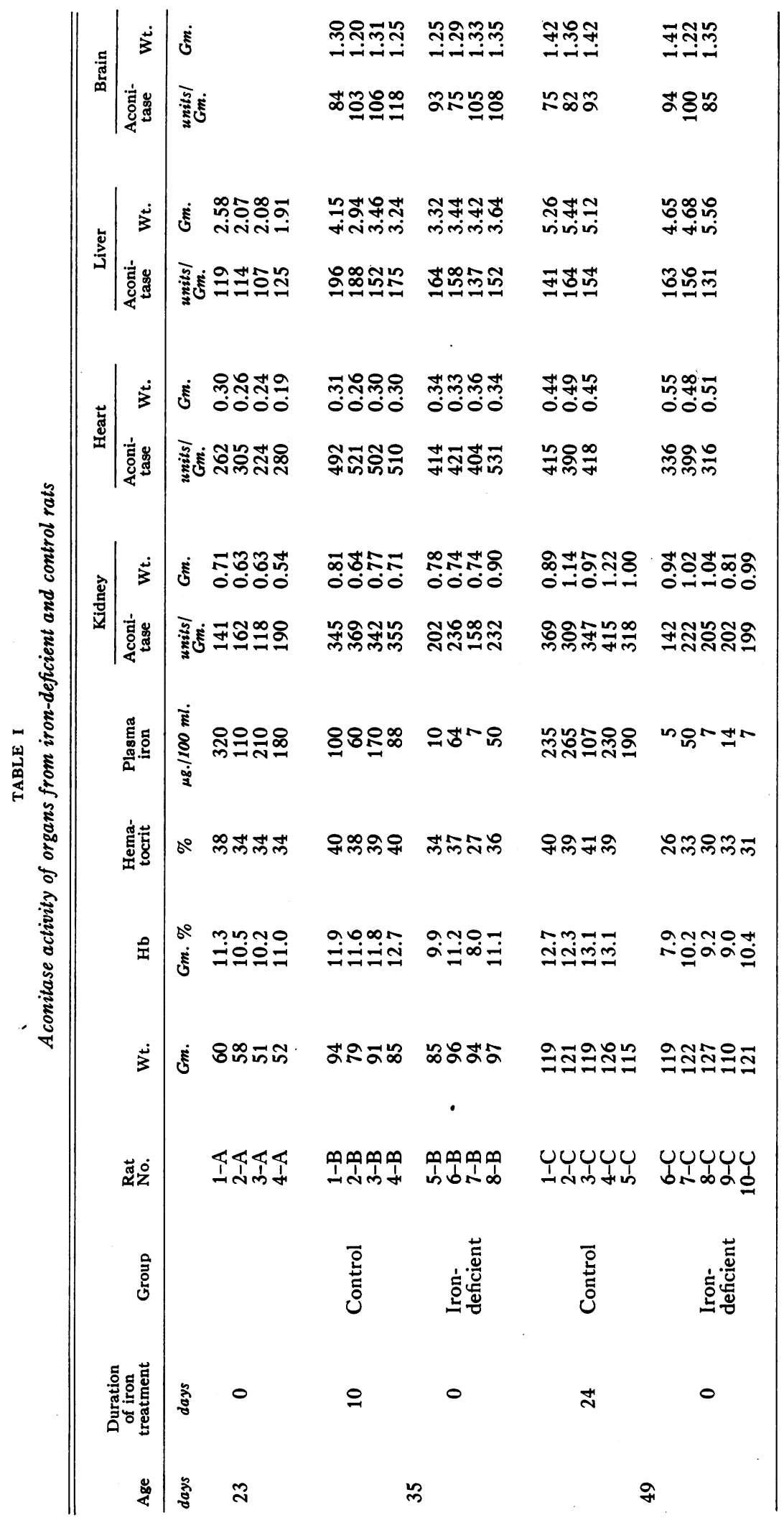




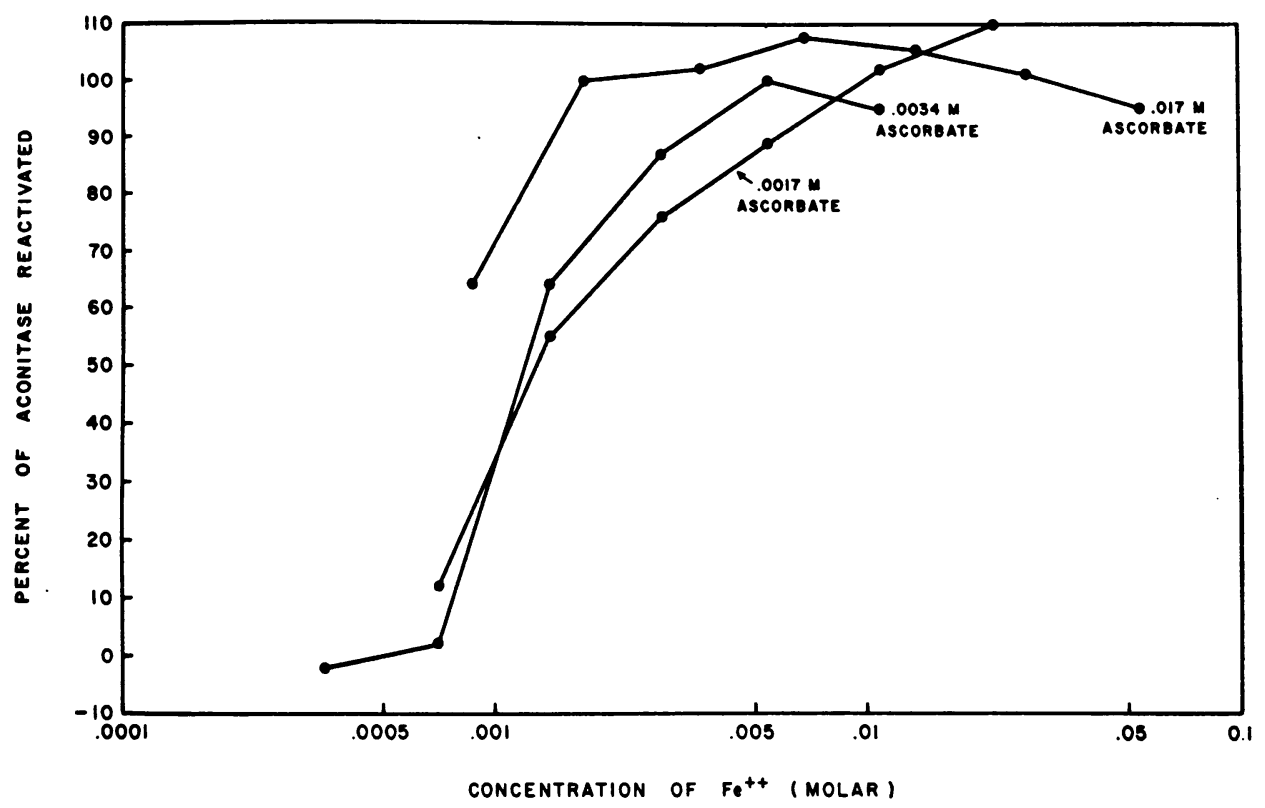

Fig. 3. The Reactivation of Aconitase by Various Concentrations of Iron and AsCORBATE

In each of the three experiments, normal rat kidney homogenate diluted one to 800 was incubated for one hour at $37^{\circ} \mathrm{C}$. The concentrations of iron and ascorbate indicated were added and an equal volume of buffer was added to a control tube. Aconitase activity was determined after an additional 10 minutes' incubation. Seventy-five to 80 per cent of the enzyme was inactivated in the control tube. The effect of iron and ascorbate is expressed as the percentage of inactivated enzyme which was reactivated.

C. An attempt to reactivate aconitase of kidneys from iron-deficient rats with iron and ascorbic acid

Tissue homogenates from iron-deficient and control rats were incubated with ascorbate and ferrous sulfate, both in final concentration of $0.003 \mathrm{M}$, for one-half hour. The aconitase activity of these homogenates was compared with that of control homogenates that had not been incubated with iron and ascorbate acid. No "reactivation" of enzyme in homogenates prepared from iron-deficient animals could be demonstrated (Figure 4). The use of ferrous sulfate and ascorbate in a higher concentration, $0.005 \mathrm{M}$, also resulted in no "reactivation." As indicated under $B$ above, normal kidney homogenate also failed to "activate" iron-deficient kidney homogenate. Similarly, $3 \mathrm{ml}$. of one to 400 normal kidney homogenate completely inactivated by heating to $100^{\circ}$ C. for five minutes or to $60^{\circ} \mathrm{C}$. for 30 minutes, or partially inactivated by incubating at $37^{\circ} \mathrm{C}$. for two hours, failed to "reactivate" iron-deficient kidney homogenate. In point of fact, approximately 33 per cent inhibition of the enzymatic activity of kidney homogenate from iron-deficient rats was observed.

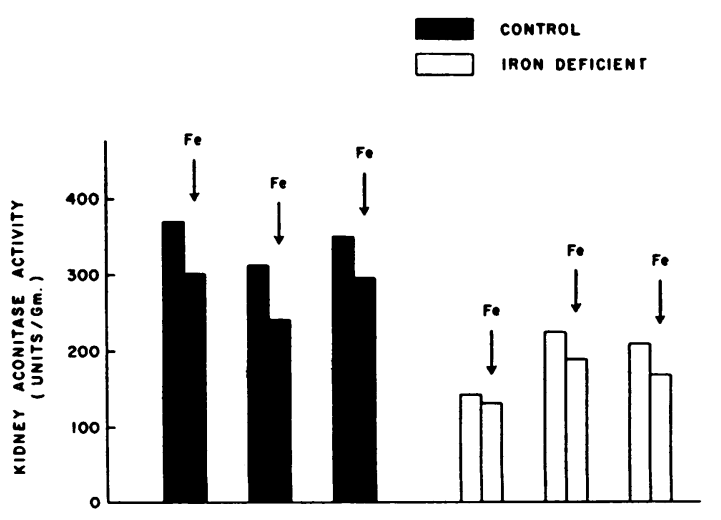

Fig. 4. The Failure of Iron and Ascorbate to "Reactivate" Aconitase from Normal and IronDeficient Rat Kidneys

Bars under arrows represent aconitase activity of homogenates that had been incubated for one-half hour with ascorbate and ferrous sulfate, both in final concentration of $0.003 \mathrm{M}$. 

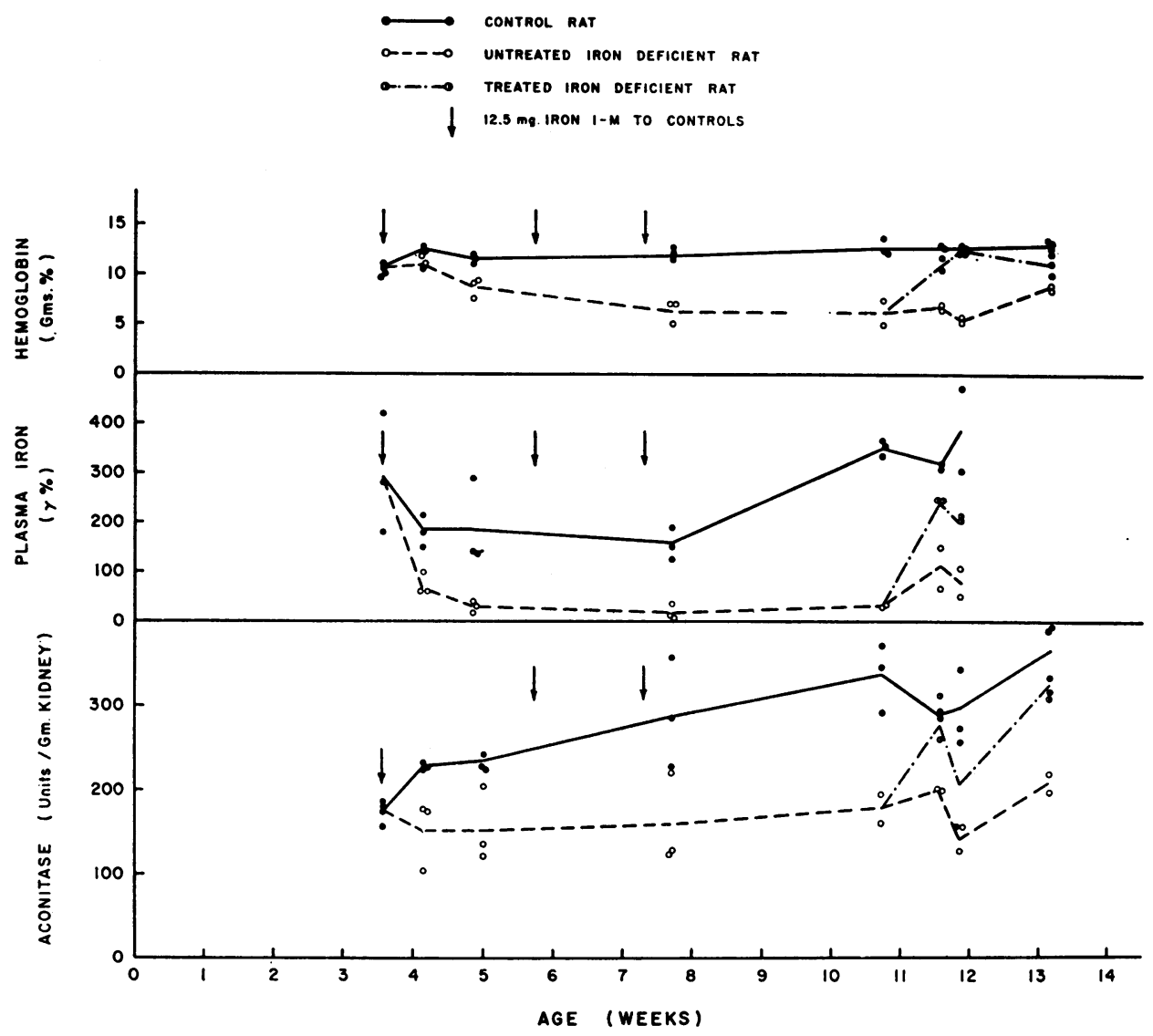

Fig. 5. The Effect of Intragastric Administration of Iron on the Hemoglobin and Plasma Iron Values, and on Kidney Aconitase Activity of Iron-Deficient Rats

Each point represents the value obtained from a single rat. The lines connect the means of each group. Intragastric iron therapy, $2 \mathrm{mg}$. $\mathrm{Fe}^{++}$per day, was initiated when the rats were 76 days old.

\section{The effect of treatment on kidney aconitase of iron-deficient animals}

A group of weanling rats was placed on an iron-poor diet. The "control" group was given $37.5 \mathrm{mg}$. of iron in the form of iron-dextran intramuscularly in three divided doses. Four animals were sacrificed at the beginning of the experiment and the hemoglobin, plasma iron and kidney aconitase were determined. Thereafter, groups of two or three animals were sacrificed at intervals, and hemoglobin, plasma iron and kidney aconitase assays were carried out. Approximately seven weeks after initiation of the experiment, one-half of the iron-deficient group was treated by the daily intragastric administration of $2 \mathrm{mg}$. of iron in the form of iron sulfate in $0.01 \mathrm{~N}$ hydrochloric acid. A prompt return of kidney aconitase activity toward normal values was observed in the iron-treated group. The individual values were too scattered to warrant conclusions about the rate of return of aconitase to normal activity, as compared with hemoglobin and plasma iron values (Figure 5).

\section{E. The effect of anemia on aconitase activity of non-iron-deficient animals}

Holtzman strain, retired male breeder rats, weighing 450 to $510 \mathrm{Gm}$., were placed on the iron-poor diet and were divided into four groups. A control group of four rats received no treatment. Another group of four animals was injected subcutaneously with 10 or $20 \mathrm{mg}$. of phenylhydrazine at two to four day intervals (Figure 6). The other two groups of six rats 
each were bled $5 \mathrm{ml}$. from the heart three times weekly for a total of six bleedings. Six of these animals were intramuscularly injected weekly with $12.5 \mathrm{mg}$. of iron as iron-dextran. Only six bled animals, three iron-treated and three untreated, survived. The average hemoglobin levels and treatment schedules of the entire surviving experimental group are presented in Figure 6. At the end of the 27 days, all animals were sacrificed and the hemoglobin, plasma iron and kidney aconitase activity were measured. The results, presented in Figure 7 , demonstrate that irondeficient rats (bled, but not treated with iron) had diminished kidney aconitase activity, even after relatively short-term iron deprivation. Anemia, induced by phenylhydrazine injections or by bleeding when iron supplements were given, failed to affect kidney aconitase activity.

\section{F. Aconitase activity of human white cells}

Semiquantitative estimation of the aconitase activity of human white cells, reported elsewhere (16), revealed a mean value of approximately 98 units per $10^{10}$ leukocytes. Aconitase determinations of the white cells of four iron-deficient subjects have given an average aconitase value of 88. All of the individual values $(106,94,77$ and 77 units per $10^{10}$ leukocytes) were within the normal range, and the difference in means is not statistically significant.

\section{G. Metabolism and excretion of a citrate load in} iron-deficient and normal subjects

Fasting subjects were given disodium hydrogen citrate, $130 \mathrm{mg}$. per $\mathrm{Kg}$. of body weight, in the form of a commercial preparation. ${ }^{3}$ Citrate

${ }^{3}$ Citralka ${ }^{\circledR}$, Parke, Davis and Co.
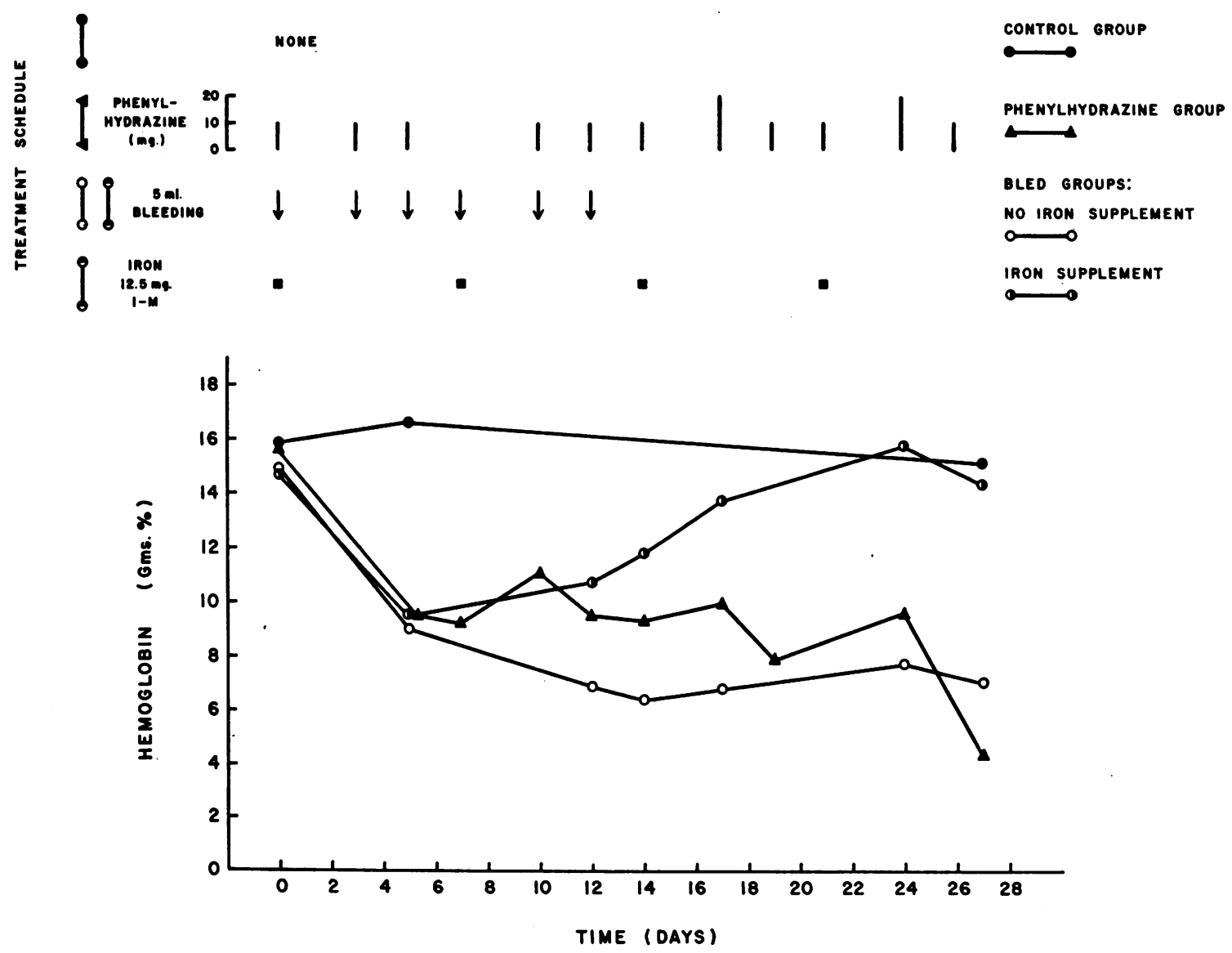

Fig. 6. Treatment Schedules and Average Hemoglobin Levels of Control Rats, Phenylhydrazine-Treated Rats, Bled Rats Injected with Iron-Dextran and Bled Rats Without Iron Supplements 


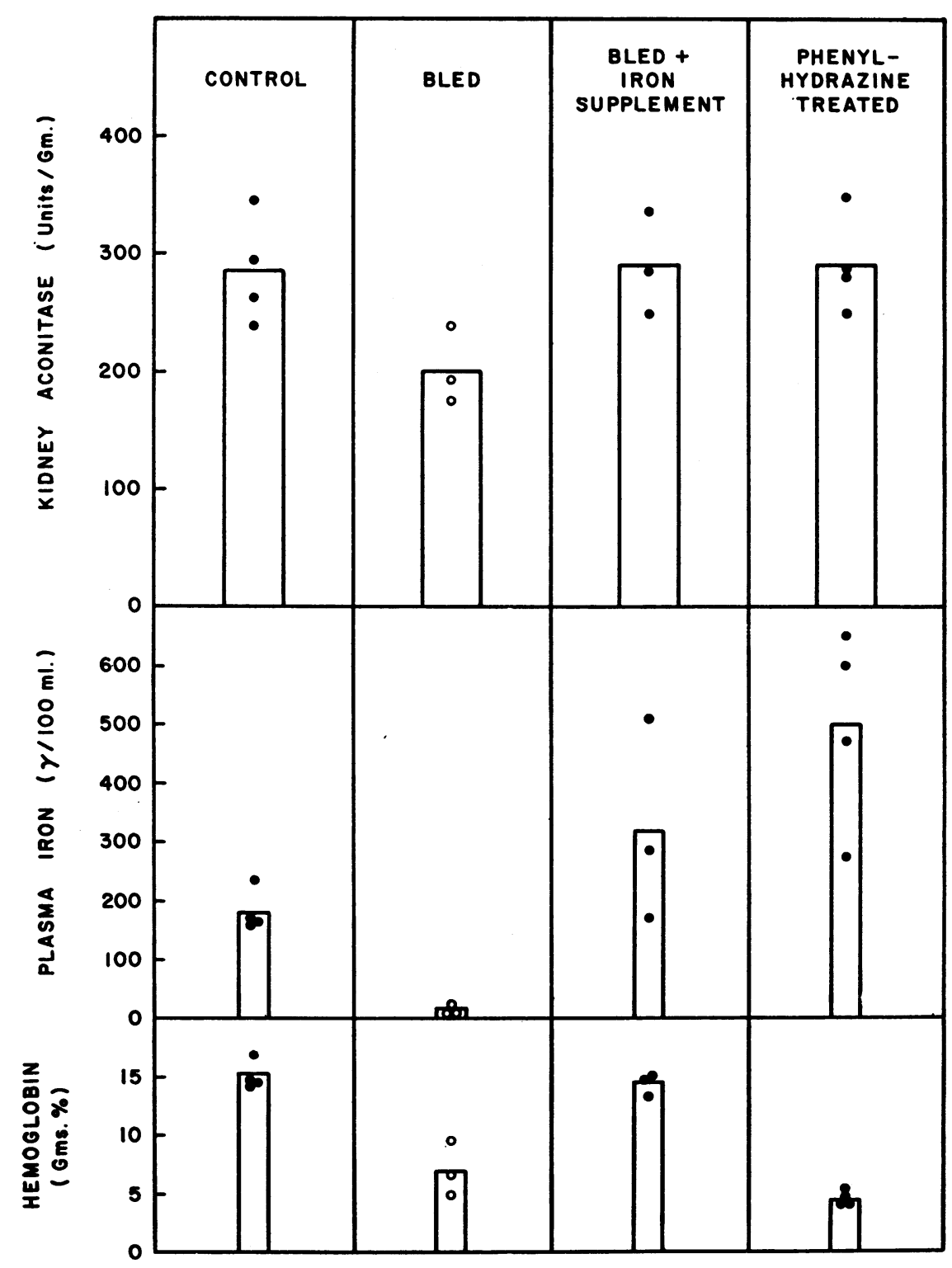

Fig. 7. The Hemoglobin Levels, Plasma Iron Values and Kidney Aconitase Activity of Control Rats, Phenylhydrazine-Treated Rats and Bled Rats Injected with Iron-Dextran and of Bled Rats Not Given Iron Supplement

levels in plasma and urine were measured before ingestion of the loading dose and at subsequent intervals. A light breakfast consisting of a roll and coffee was given one hour after administration of citrate. The results of studies carried out in three normal and six iron-deficient subjects are shown in Figure 8. Pertinent clinical and hematologic data are presented in Table II. The slightly higher plasma average levels and lower cumulative urinary citrate excretion of the iron-deficient subjects are deemed to be of little importance. In one mildly iron-deficient subject with high urinary citrate excretion, repeated measurements were made of six hour urinary citrate excretion following standard loading, both before and after iron therapy. No change in citrate excretion could be demonstrated (Figure 9). 
DISCUSSION

A decrease in aconitase activity has been demonstrated in the kidneys of iron-deficient rats. Weanling rats deprived of iron failed to develop the rapid increase in kidney aconitase activity that occurs when iron is administered to young rats. The activity of this enzyme decreased in mature animals rendered iron-deficient by repeated bleeding while on an iron-poor diet. It is of particular interest that the decrease in enzymatic activity in kidneys from iron-deficient rats did not appear to be due merely to a lack of iron acting as a cofactor for aconitase activity. since addition of iron failed to "reactivate" aconitase from iron-deficient animals. Normal kidney tissue also failed to reactivate enzyme from iron-deficient kidneys, and it may therefore be presumed that the decrease of aconitase activity was due to actual depletion of the protein moiety of the enzyme. In this respect, aconitase may be regarded to be similar to apoferritin, which is synthesized in response to iron (18), and to the

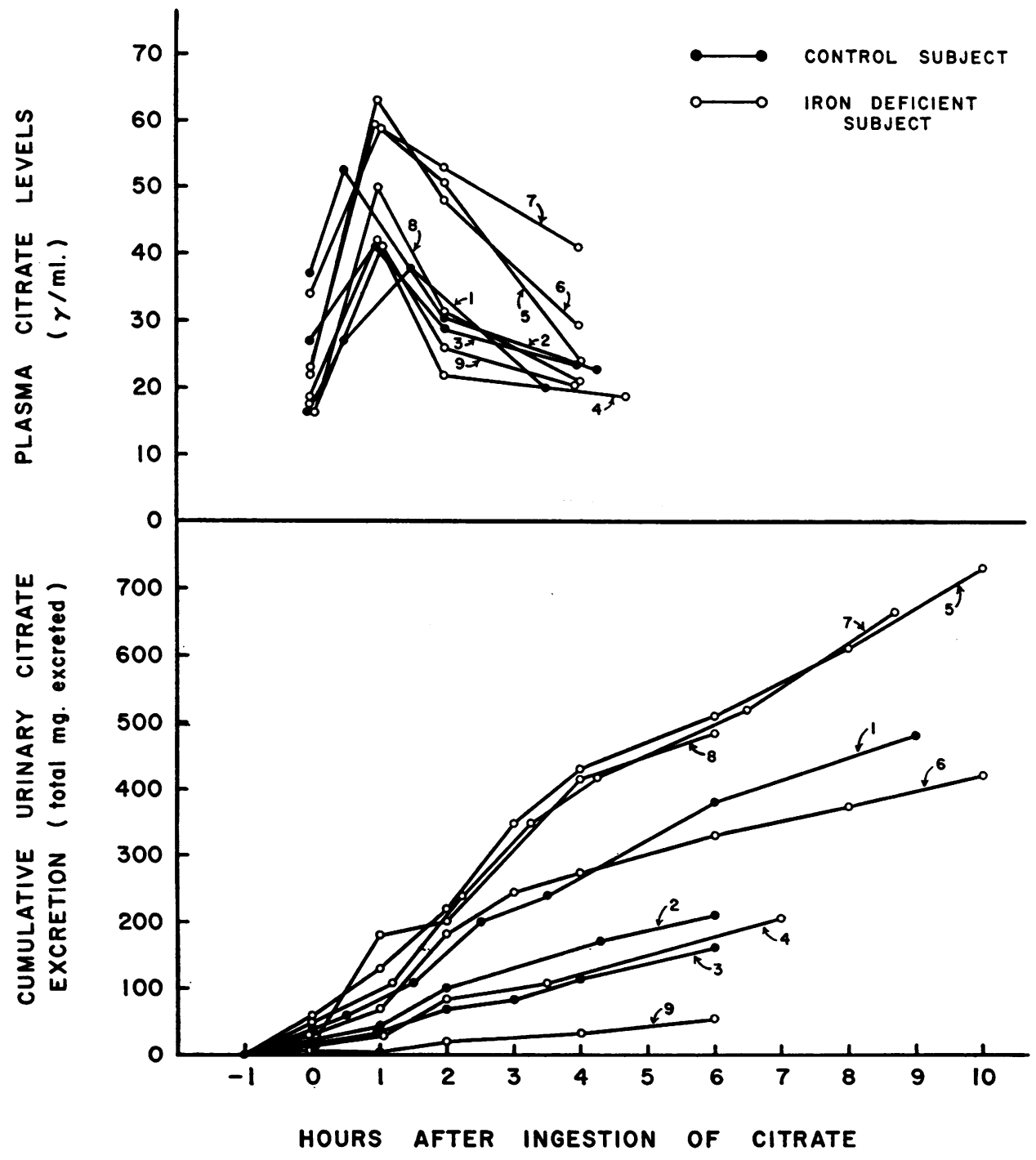

Fig. 8. Plasma Citrate and Cumulative Urinary Citrate Excretion in Three Normal and Six Iron-Deficient Subjects

At time $=0,130 \mathrm{mg}$. of disodium hydrogen citrate was given per $\mathrm{Kg}$. of body weight. Pertinent clinical and hematological data for each patient are given in Table II. 
TABLE II

Clinical and laboratory findings of nine subjects studied after citrate loading

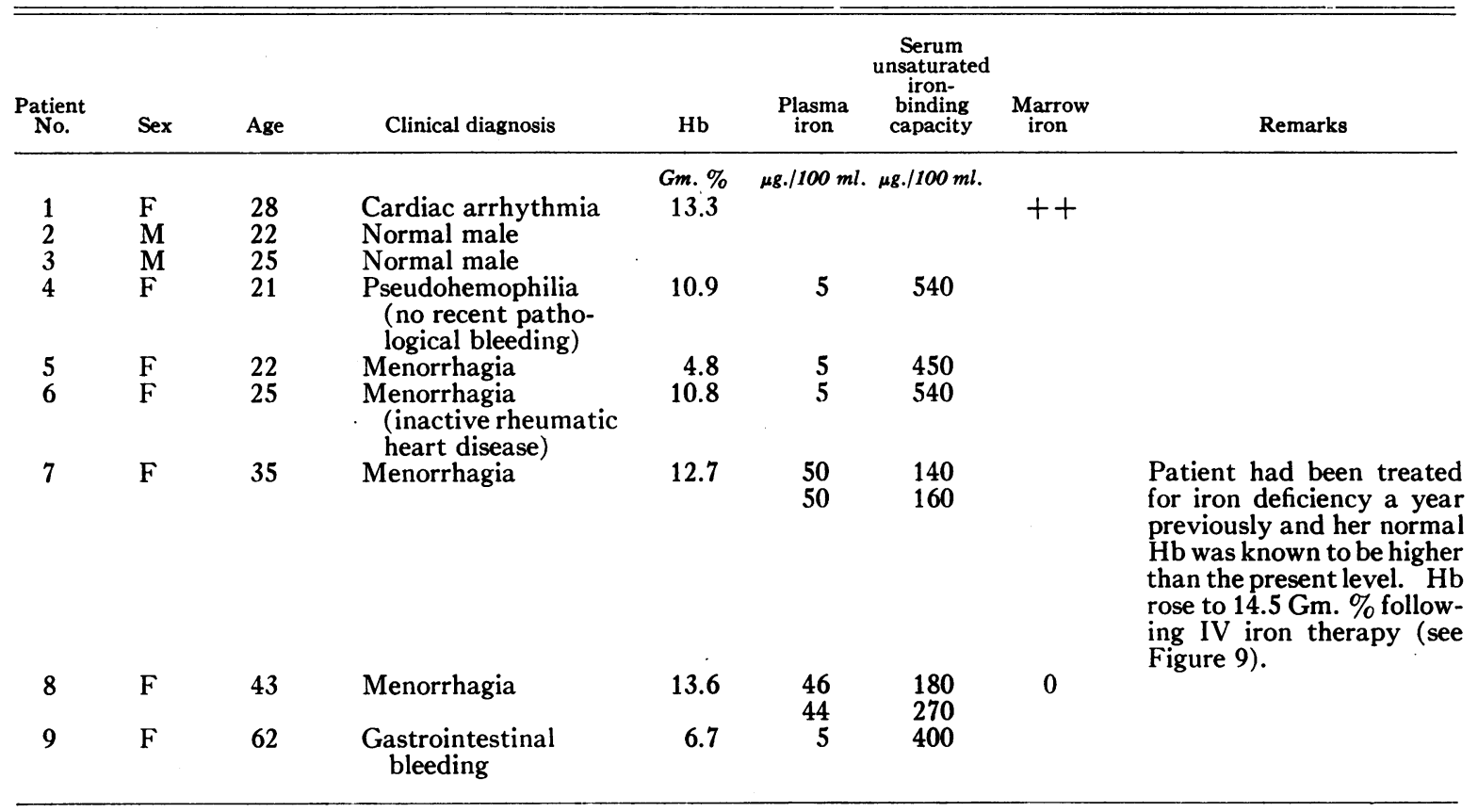

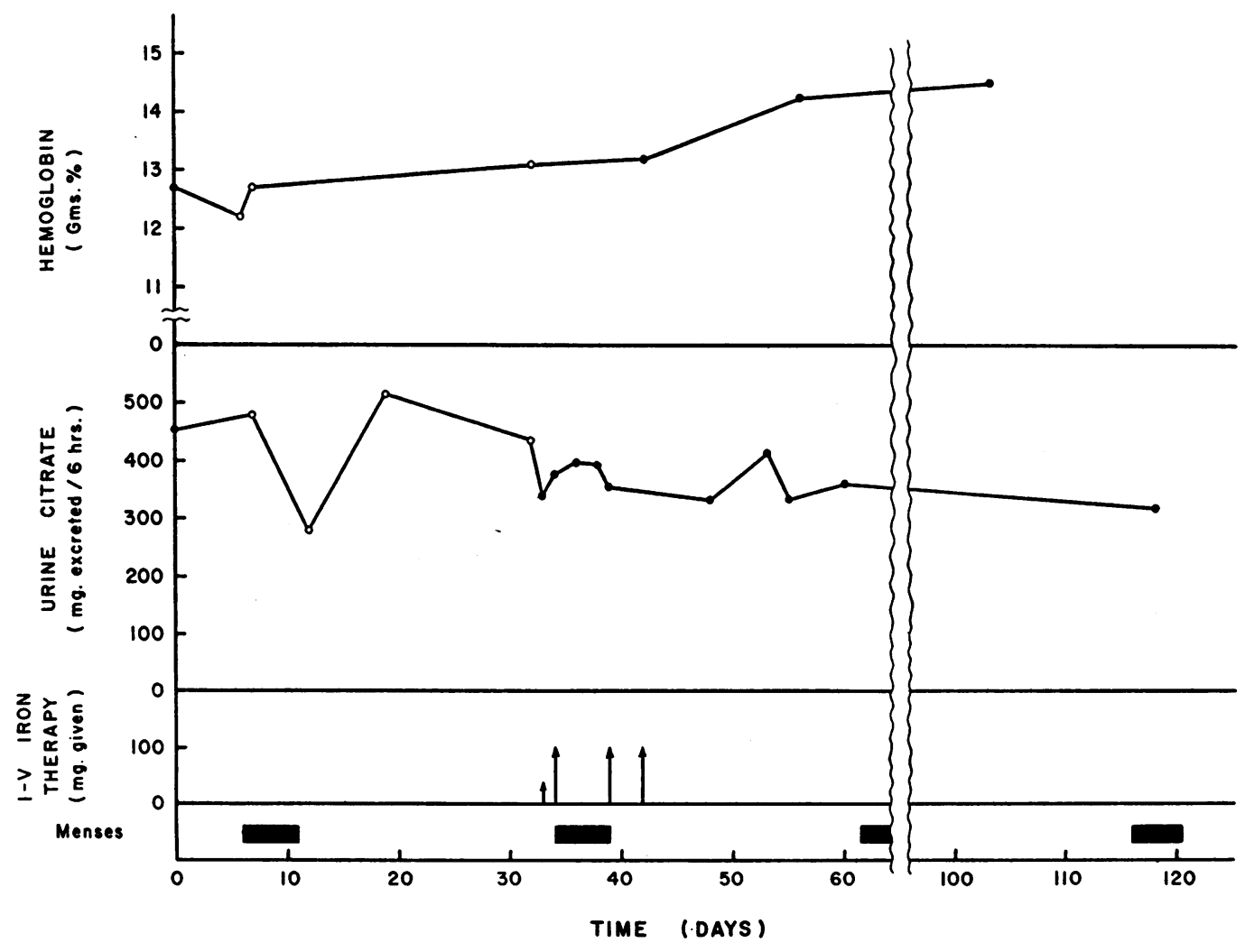

Fig 9. Cumulative Six Hour Urinary Citrate Excretion of Subject No. 7

Measurements of citrate excretion were made following oral citrate loading on repeated occasions, before and after intravenous administration of iron in the form of saccharated iron oxide. 
globin moiety of hemoglobin, synthesis of which appears to be inhibited in iron deficiency (19).

Takeda and Hara (14) have reported that poisoning with $\alpha$ - $\alpha^{\prime}$-dipyridyl results in greatly. increased urinary excretion of citric acid by guinea pigs, especially after they had been fed large quantities of citrate and butyrate. Using rats as the test animal, we have been unable to duplicate these results, using our modification of the pentabroacetone method for citrate analysis (16). The less specific sodium sulfide (20) method used by Takeda and Hara gives a false positive reaction for citric acid with $\alpha$ - $\alpha^{\prime}$-dipyridyl (21). It is possible that Takeda and Hara measured $\alpha$ - $\alpha^{\prime}$-dipyridyl, or a metabolic product as citric acid. However, even true citric aciduria, if it occurs under these experimental conditions, does not necessarily indicate profound changes in intracellular citric acid metabolism: citric acid excretion is extremely sensitive to urine $\mathrm{pH}$ changes (22).

In spite of our failure to confirm the results of Takeda and Hara in rats, we studied citric acid excretion in iron-deficient and normal subjects following loading with citric acid, hoping that a clinically useful means for diagnosis of iron deficiency might emerge. However, no significant difference was observed either in blood or urine citrate levels of iron-deficient and normal subjects. Obviously, this does not prove that the operation of the citric acid cycle is normal in iron-deficient subjects: the metabolism of an exogenously administered dose of citrate may be quite different from that of citrate produced within the cell by condensation of acetate and oxalacetic acid.

\section{SUM MARY}

1. The observation of Dickman and Cloutier $(5,13)$, that inactivated solutions of aconitase may be reactivated by iron and a reducing agent, has been confirmed.

2. The aconitase activity of kidneys from irondeficient rats was found to be reduced consistently, but the aconitase activity of the hearts, livers and brains of iron-deficient rats was normal.

3. Aconitase from the kidneys of iron-deficient rats could not be "reactivated" by the addition of iron and ascorbate, homogenate of normal rat kidney, or heat-inactivated normal rat kidney homogenate. This finding is interpreted as indicating an actual depletion of the protein moiety of aconitase in iron-deficient animals.

4. Treatment of iron-deficient rats with iron restored their kidney aconitase activity to normal.

5. Anemia, induced by the administration of phenylhydrazine or by repeated bleeding of rats given supplemental iron, failed to reduce kidney aconitase activity; blood loss anemia in rats not given iron supplement resulted in a decrease in kidney aconitase activity.

6. Aconitase activity of human white blood cells from iron-deficient subjects was found to be normal.

7. Plasma citrate levels and urinary citrate excretion after oral loading with citrate has been studied. No difference could be demonstrated between normal and iron-deficient subjects.

\section{REFERENCES}

1. Kearney, E. B., and Singer, T. P. On the prosthetic group of succinic dehydrogenase. Biochim. biophys. Acta 1955, 17, 596.

2. Shorr, E. Intermediate metabolism and biological activities of ferritin. Harvey Lectures, 1954-55, 50, 112.

3. Patwardhan, M. V. Role of ferrous iron in enzymatic transamination. Nature (Lond.) 1958, 181, 187.

4. Suda, M., and Takeda, Y. Metabolism of tyrosine. II. Homogentisicase. J. Biochem. (Tokyo) 1950, 37, 381.

5. Dickman, S. R., and Cloutier, A. A. Activation and stabilization of aconitase by ferrous ions. Arch. Biochem. 1950, 25, 229.

6. Beutler, E. Iron enzymes in iron deficiency. I. Cytochrome C. Amer. J. med. Sci. 1957, 234, 517.

7. Beutler, E., and Blaisdell, R. K. Iron enzymes in iron deficiency. III. Catalase in rat red cells and liver with some further observations on Cytochrome C. J. Lab. clin. Med. 1958, 52, 694.

8. Beutler, E., and Blaisdell, R. K. Iron enzymes in iron deficiency. II. Catalase in human erythrocytes. J. clin. Invest. 1958, 37, 833.

9. Beutler, E. Iron enzymes in iron deficiency. IV. Cytochrome oxidase in rat kidney and heart. Acta Haemat. (Basel) 1959, 21, 371.

10. Beutler, E. Iron enzymes in iron deficiency. V. Succinic dehydrogenase in rat liver, kidney, and heart. Blood. In press.

11. Hahn, P. F., and Whipple, G. H. Iron metabolism. II. Its absorption, storage and utilization in experimental anemia. Amer. J. med. Sci. 1936, 191, 24. 
12. Gubler, C. J., Cartwright, G. E., and Wintrobe, M. M. Studies on copper metabolism. XX. Enzyme activities and iron metabolism in copper and iron deficiencies. J. biol. Chem. 1957, 224, 533.

13. Dickman, S. R., and Cloutier, A. A. Factors affecting the activity of aconitase. J. biol. Chem. 1951, 188, 379.

14. Takeda, Y., and Hara, M. Significance of ferrous ion and ascorbic acid in the operation of the tricarboxylic acid cycle. J. biol. Chem. 1955, 214, 657.

15. Anfinsen, C. B. Aconitase from pig heart muscle in Methods in Enzymology, S. P. Colowick and N. O. Kaplan, Eds. New York, Academic Press Inc., 1955, vol. I, p. 695.

16. Beutler, E., and Yeh, M. K. Y. A simplified method for the determination of citric acid. J. Lab. clin. Med. 1959, 54, 125.
17. Beutler, E., and Yeh, M. K. Y. Aconitase in human blood. J. Lab. clin. Med. In press.

18. Granick, S. Ferritin. IX. Increase of the protein apoferritin in the gastrointestinal mucosa as a direct response to iron feeding. The function of ferritin in the regulation of iron absorption. J. biol. Chem. 1946, 164, 737.

19. Beutler, E. Iron content of haemoglobin in iron deficiency. Nature (Lond.) 1958, 181, 837.

20. Lardy, H. A. Method for citric acid in Manometric Techniques, W. W. Umbreit, R. H. Burris and J. F. Stauffer, Eds. Minneapolis, Burgess Publishing Co., 1957, p. 240.

21. Beutler, E. Unpublished observations.

22. Östberg, V. O. Studien über die zitronensäureausscheidung der menschenniere in normalen und pathologischen zuständen. Skand. Arch. Physiol. 1931, 62, 81. 